\title{
El valor de la libertad en el derecho: ¿vivir como cada uno quiera?
}

\section{The Value of Freedom in the Law: Should Everyone live like they want to?}

Fecha de recepción: 10 de agosto de 2010 Fecha de aprobación: 18 de noviembre de 2010

\author{
Édgar Antonio Guarín Ramírez*
}

\section{Resumen}

En los últimos años, a la par que se ha venido considerando a la libertad como uno de los valores jurídicos más importantes, aumentan en nuestra sociedad la inseguridad, el desorden, la violencia, la injusticia... Eso tiene que llevarnos a pensar, si existe o no alguna relación entre esa plusvalía de la libertad en que vivimos actualmente, y la decadencia de los demás valores jurídicos, especialmente de la justicia. Quienes nos dedicamos al análisis iusteórico o iusfilosófico del derecho, tenemos el imperativo de empezar a estudiar con profundidad el auténtico significado de la libertad humana como valor jurídico, para así poder contribuir a la recuperación del derecho y la justicia.

Palabras clave: persona, libertad, justicia, realismo, idealismo, educación, derecho.

Docente e investigador, perteneciente a la línea Pensamiento Ético Político y Jurídico de Santo Tomás de la Facultad de Derecho. Magíster en Derecho Público de la Universidad Santo Tomás. Correo electrónico: edguarin@hotmail.com 


\begin{abstract}
In recent years, freedom has been considering as one of the most important legal values, simultaneously however insecurity, disorder, violence and injustice keep increasing in our society. This lead us to think, whether or not any relationship exists between this ever increasing realm of freedom in which we live today, and the decline of other legal values and justice. Those amongst us who are dedicated to the iustheoretical and iusphilosophical analysis of the law, have the imperative to start studying in depth the true meaning of human freedom as the legal value, to contribute to the recovery of law and justice.
\end{abstract}

Key words: person, freedom, justice, realism, idealism, education, law.

\section{INTRODUCCIÓN}

Al finalizar una conferencia que dictaba en el marco de la XXXIII Semana Tomista celebrada en Buenos Aires hace algunos meses, uno de los asistentes -haciendo eco de las principales ideas desarrolladas en el curso de mi reflexión- me relató lo sucedido con un niño (casi adolescente) que se econtraba miccionando en los alrededores de la Casa Rosada; uno de los guardias le sorprendió y le dijo que eso "no lo podía hacer", ante lo cual el chico respondió: icómo así!, ¿no ve que "estoy pudiendo"? La respuesta del muchacho -decía aquel maestro-, revela la existencia de una tendencia actual muy fuerte a considerar que ser libre es hacer lo que se "quiere, puede y no da miedo", y garantizarle al otro que él también lo pueda hacer: así, ambos somos felices. Pero... ¿ ieso es ser libre?

El hecho narrado por el profesor argentino, afirmó mi convicción de que la libertad constituye uno de los temas más importantes de análisis en la actualidad, del cual los juristas no nos podemos sustraer dado que, hoy por hoy, la libertad es uno de los valores de rango constitucional más importantes -quizá el más importante-, cuya protección es recurrentemente solicitada por los ciudadanos ante los jueces. Los caminos recorridos por el alto tribunal constitucional colombiano en este campo le han llevado a considerar la libertad como elemento fundamental para la plena realización humana dentro del Estado Social de Derecho proclamado en la Carta de 1991. En los múltiples fallos proferidos por la Corte Constitucionial ha sido recurrente el considerar el acto libre como sinónimo de autonomía: capacidad de hacer o no hacer lo que el sujeto considere conveniente, lo cual ha sido puesto, además, como el principio que irradia a todos los demás derechos consagrados en la Carta Política de 1991. Sentencias como la $\mathrm{T}-222 / 92$, T-524/92, T-542/92, T-1207/ 2000, entre muchas otras, muestran que para la Corte, la libertad vista como autonomía, constituye el principio que irradia a todos los derechos contenidos en la Constitución, pues otorga mayor fuerza a su contenido. La libertad constituye, hoy por hoy, el eje gravitacional sobre el que se hacen girar los demás derechos fundamentales.

Esta misma línea se ha seguido en fallos de constitucionalidad, como es el caso de la Sentencia C-221/94, que trató sobre la despenalización de la dosis mínima, en donde, siguiendo concepciones dworkinianas que ven en el derecho el medio para que los individuos se defiendan de la sociedad, se dijo que había que vigilar que el Estado no desconociera la autonomía que poseen los individuos sobre la escogencia de su rumbo de vida. La drogadicción, dice el fallo, aunque indeseable, es una decisión que sólo compete al individuo, por cuanto es un camino que no afecta los derechos ajenos, no siendo posible alegar la dañosidad general, debido a que el daño debe darse en concreto y no en abstracto. Dentro de este marco intelectivo de 
la libertad, los reglamentos estudiantiles, al igual que los ordenamientos internos de entidades privadas o públicas, han tenido que irse acomodando al libre desarrollo de la personalidad de quienes integran las diversas comunidades.

Por esta ruta, la libertad se ha venido constituyendo poco a poco, en un valor jurídico de tal relevancia, que de unos años para acá la Corte ha venido sosteniendo que cuando se habla de la dignidad humana como "un criterio relevante para decidir, se entiende que ésta protege: (i) la autonomía o posibilidad de diseñar un plan vital y de determinarse según sus características (vivir como se quiere)..." (C-355/06). Así pues, la dignidad humana coincide con la autonomía personal: una libertad de no ser obstaculizado, y una libertad para hacer lo que cada uno quiera según su voluntad, pues como se afirma en la Sentencia C-309/97, en un Estado democrático, no es posible hablar de perfección del hombre en un único sentido, puesto que:

[...] en Colombia, las políticas perfeccionistas se encuentran excluidas, ya que no es admisible que en un Estado que reconoce la autonomía de la persona y el pluralismo en todos los campos, las autoridades impongan, con la amenaza de sanciones penales, un determinado modelo de virtud o de excelencia humana. En efecto, esas políticas implican que el Estado sólo admite una determinada concepción de realización personal, lo cual es incompatible con el pluralismo. Además, en virtud de tales medidas, las autoridades sancionan a un individuo que no ha afectado derechos de terceros, únicamente porque no acepta los ideales coactivamente establecidos por el Estado, con lo cual se vulnera la autonomía, que etimológicamente significa precisamente la capacidad de la persona de darse sus propias normas [...] (Sentencia C-309/97).

Lógicamente, si bien la libertad es autonomía y hay que defenderla, la Corte ha sido consciente de que no es posible hablar de la protección de una absoluta autonomía, dados los problemas sociales que conlleva tal concepción; por eso, siempre ha hablado de ciertos límites al libre desarrollo de la personalidad. En la sentencia T-429/94, M.P. Barrera Carbonell, por ejemplo, se confirma y enfatiza la tesis de la Corte en "pro de la libertad", pero se dice que ella tiene unas limitaciones que son: los derechos de otros y las obligaciones legales. Sobre estos límites de la libertad, también las referencias del alto tribunal son recurrentes.

Esta "inflación" de la libertad como valor jurídico ha sido tan grande que, incluso, se le ha puesto por encima de la justicia, valor que desde antaño ha constituido, nada más y nada menos, que el objeto formal de la ciencia del derecho. Que eso es así, se demuestra con el hecho de que nadie niega que, cuando a una persona se le priva de un medicamento que es necesario para calmar su dolor o recuperar su salud, se comente un grave acto de injusticia; contrario sensu, el acto de justicia radica en darle al otro eso que es suyo, su ius -como dirían los romanos- que en este caso, es el medicamento. Pero también es un lugar común el aceptar que la vida es un derecho que nos pertenece a todos los seres humanos; incluso hoy se defiende con tenacidad el derecho a vivir de muchas especies animales. Por eso, ideas como las de implantar la pena de muerte en Colombia tienen tanta resistencia. Cegar la vida a otro es un terrible acto de injusticia, pues con ello se le despoja de un derecho inherente a su ser, un derecho que, según nuestra Constituición, es fundamental. Empero, en aras de defender la libertad de la mujer, muchos Estados -entre ellos el nuestro- han abierto las puertas a la violación de la vida del nasciturus. Y aunque algunos digan que la cuestión es eminentemente moral, la verdad de las cosas es que se trata de un asunto jurídico, pues lo que está en juego es el bien jurídico más importante: la vida humana.

Es interesante ver cómo, a la par que se ha venido considerando a la libertad como el valor jurídico por excelencia, aumentan en nuestra sociedad la 
inseguridad, el desorden, la violencia, la secesión, la injusticia... Eso tiene que llevarnos a pensar, si existe o no, alguna relación entre la magnificación de la libertad que vivimos actualmente, y la decadencia de los demás valores jurídicos. Por eso, quienes nos dedicamos al análisis iusteórico o iusfilosófico del derecho, tenemos el imperativo de empezar a estudiar con profundidad el auténtico significado de la libertad humana como valor jurídico, para así, poder contribuir al mejoramiento de nuestras instituciones. Seguramente, las reflexiones contenidas en este sucinto escrito entrarán en las huestes de lo que, para muchos apegados a la tradición positivista en todas sus manifestaciones -incluidas las tendencias procedimentalistas que hacen un fuerte énfasis en la axiología jurídica- hacen parte de lo "impuro" del derecho, toda vez que en ella se incluyen términos como los de naturaleza humana, verdad, bien, etc. Sin embargo, lo que me motiva a escribir no es la aceptación o no aceptación de algunos o de muchos, sino la verdad de las cosas.

En esta pequeña disertación, analizo las dos perspectivas desde las cuales, a mi juicio, es posible abordar el tema de la libertad humana: una, heredada del idealismo moderno -del cual Kant es el gran pedagogo-, desarrollada por teóricos como Berlin, Rawls, Bobbio, Dworkin, Kaufmann, Atienza, Alexy, entre muchos otros (cada uno con sus matices); otra, inspirada en el realismo filosófico clásico, contenida en el pensamiento de académicos como E. Gilson, J. Hervada, C. Cardona, Millán Puelles, M. Villey, Maritain, Derisi, Gevaert, Yepes, etc.; todos ellos, inspirados en la filosofía de Aristóteles y del gran maestro medieval Tomás de Aquino. La primera -la del idealismo moderno-, seguida hasta ahora por la Corte Constitucional de manera mayoritaria, la cual considera que el fundamento de la libertad está en el sujeto, en su autonomía de voluntad, en su "razón" práctica; la segunda -la del realismo aristotélico-tomista-, plenamente consciente de que la libertad sólo se puede predicar del hombre, concibe el acto libre como acto humano y, en cuanto tal, acto de inteligencia y voluntad; por esa vía, estima que si el acto "libre" hace abstracción de la naturaleza humana y no da cuenta de la verdad y del bien como objetos propios de la inteligencia y la volutad, no es auténticamente acto de libertad.

Como conditio previa, he de llamar la atención respecto de la actitud recurrente por parte de algunos de los principales iusfilósofos o iusteóricos de las últimas décadas, su negativa a aceptar que la fundamentación de sus teorías, tenga algo que ver con la metafísica. La explicación de este fenómeno se halla -entre otras cosas- en el antropocentrismo heredado de la modernidad llevado a su culmen por la filosofía trascedental kantiana, con lo que se sustituyó el concepto de "ente", por el concepto de "objeto", lo cual, a su vez, generó el hecho de que se dejara en manos del hombre -de su racionalidad- la determinación de lo real; consecuencia de lo anterior, ha sido la pretensión propia del positivismo científico de alcanzar conocimientos "puros" dentro las diferentes áreas del saber, con lo cual se busca eliminar todo aquello que no sea "científico", y a lo cual se le dio, además, el calificativo de "metafísico". Herencia de esta manera de concebir la filosofía, es también el pensamiento analítico, conceptos tales como el de esencia, substancia, ente, naturaleza, etc., propios de la "filosofía primera", son considerados "no empíricos" y, por ende, carentes de sentido. La filosofía analítica ha pretendido hacernos creer que los conceptos no guardan correspondencia con esencias de ningún tipo, sino que son el producto de los usos lingüísticos de la comunidad. Esta forma de entender el conocimiento ha permeado todos los ámbitos del saber; entre ellos el del derecho y, más específicamente, lo atinente al sentido de la libertad humana, objeto de analísis de este escrito. Aunque parezca una "teoría impura" sobre la libertad, que escapa a los modelos procedimentalistas que son predominantes en la actualidad, estamos convencidos que al abandonar el horizonte metafísico en el cual se 
enraíza la libertad, el hombre de hoy, en aras de alcanzar y desarrollar una "mayor libertad", termina relativizando su significado y contenido, como la libertad refiere de manera directa a la especial excelencia y dignidad que tiene el ser humano, dignidad y libertad terminan sumidas en el más profundo vacío. Así, el Libre Desarrollo de la Personalidad (LDP), tan avalado y ponderado por los constitucionalistas, se ha convertido en nuestras sociedades, en una "Libertad para la Destrucción de la Persona" (LDP).

Metodológicamente sigo la técnica de la disertación: primero abordo la tesis sostenida por el idealismo moderno respecto de la libertad; prosigo mostrando su antítesis en el pensamiento realista; $y$, finalmente, hago una síntesis en la cual muestro el que, a mi juicio, es el camino para volver a recuperar el sentido auténtico de la libertad humana: la educación, que tiene mucho que ver con la ley, pues ella tiene una marcada función educadora dentro de la sociedad. La actitud con la que ha sido escrita cada palabra de este texto, es de apertura y diálogo, a la vez que de profundo respeto por la verdad -actitud propia de quien sigue el espíritu tomista, que acoge la verdad venga de donde venga-; a la vez, con un ánimo sincero de contribuir a la reflexión actual que se hace respecto de la libertad, muy especialmente, dentro del mundo jurídico y, más específicamente, en el campo constitucional.

\section{TESIS: LA LIBERTAD ES VIVIR COMO SE QUIERA, SUS LÍMITES: LA LIBERTAD DEL OTRO Y EL ORDEN JURÍDICO}

Actualmente, la libertad está siendo explicada con referencia a tres cosas: 1 . los agentes. 2. las restricciones o límites de los que están libres. 3. libertad de hacer o no hacer. John Rawls, el gran filósofo norteamericano de finales del siglo pasado, heredero del contractualismo y del kantismo, en su libro Teoría de la justicia, da cuenta de esta forma de concebir la libertad al describirla en estos términos: "esta o aquella persona está libre de esta o aquella restricción o restricciones para hacer o no hacer tal o cual cosa" (Rawls, 2000, p. 192). Con esta definición, Rawls trata de superar el debate berliniano respecto de si la libertad es sólo una libertad de, o implica una libertad para - libertad negativa y libertad positiva-, afirmando que la libertad es a la vez negativa y positiva, y que encuentra sus límites en las libertades ajenas. La libertad así concebida es tan importante para Rawls, que constituye el primer principio de la justicia, lo que equivale a afirmar que cualquier limitación "injustificada" de la libertad configura un acto de injusticia.

Desde los albores de la modernidad, la fundamentación de la libertad, fue referida al hombre, de quien se predicó una naturaleza racional y libre; un ser capaz de comprender que lo primero que hay que garantizar al interior de una sociedad que propenda por alcanzar una auténtica justicia social, es el más amplio reconocimiento de las libertades de los individuos. Ese "sistema" de libertades está integrado desde entonces, principalmente, por las libertades de conciencia, de pensamiento, de expresión, de reunión, etc., que se encuadran dentro de una compleja estructura de derechos y deberes, al interior de los cuales, el más importante, es el del respeto por las libertades del otro. Así, la libertad fue presentada desde otrora, como un derecho y un deber: derecho de hacer o no hacer, y deber de respetarle al otro su decisión respecto de aquello que quiera hacer o dejar de hacer, siendo el ordenamiento jurídico -las normas y la jurisprudencia- el medio más idóneo para garantizar este derecho-deber.

Ahora bien, cuando se habla dentro de este marco epistemológico de "naturaleza humana" es preciso enfatizar en que dicho concepto nada tiene que ver con lo "metafísico". Lo natural refiere fundamentalmente a aquello que es un producto de la racionalidad humana; y como el hombre es un ser individual y social, lo natural termina siendo 
aquello que es determinado por el hombre de manera subjetiva, o de manera consensuada. Así pues, aunque la persona es libre y racional "por naturaleza", y esa libertad y racionalidad son bienes primarios, el contenido de esa libertad se deja en manos de la persona o de las personas puestas en diálogo, porque eso hace parte del significado mismo de lo que es "natural". Como lo afirma con paladina claridad Rawls: "antes de la celebración del contrato (que va a dar lugar a los principios de justicia), conceptos como los de bien, dignidad y libertad, tienen un contenido indefinido" (Rawls, 2000, p. 258). En síntesis, para la tradición heredada de la modernidad, la libertad es un bien, un bien primario; pero ese bien depende de lo que cada uno considera que es el bien, según su proyecto de vida; esa libertad, lógicamente, no es arbitrariedad porque su límite está en la libertad del otro y el ordenamiento jurídico.

La idea de una completa libertad había sido puesta sobre el tapete de la reflexión filosófica por John Locke en el Segundo ensayo sobre el gobierno civil al analizar el fundamento del poder político. Allí habla de una "completa libertad" de los hombres para ordenar sus actos y para disponer de sus propiedades $y$ de sus personas como mejor les parez$\mathrm{ca}$, sin necesidad de pedir permiso y sin depender de la voluntad de otra persona: sería el contrato o pacto social el que determinaría la manera en que ello se pueda garantizar. Lo anterior explica por qué existe una desmesurada presencia del tema de los derechos subjetivos en el liberalismo: se tiende a hacer de la mera libertad un verdadero derecho subjetivo, es decir, algo de suyo lícito y valioso que debe ser respetado; como el hombre no abdica de sus derechos "naturales" con el pacto social, como sucedía con Hobbes, el fin del Estado está en la preservación de los derechos subjetivos, sea por parte del poder público, sea de los demás ciudadanos. La comunidad -el Estado- aparece entonces como un "mal necesario" que debe ser restringido al máximo, en aras de garantizar mayor libertad a cada persona. Desde entonces, la libertad empezó a ser vista desde dos aspectos relevantes en el campo de la política y del derecho: negativo -que nadie se interponga- $y$ positivo -libertad para desplegar la autonomía, para disfrutar de los bienes temporales-.

La influencia de esta concepción de la libertad en las políticas actuales y en las decisiones de la Corte Constitucional descritas en la introducción de este trabajo, es innegable; no se puede olvidar que la justicia como igualdad planteada por Rawls, ha encontrado muchos adeptos en el campo de la teoría del derecho; el famoso "libro verde", como se le conoció originalmente a la Teoría de la justicia, le ha dado la vuelta al mundo occidental, e inspira muchas de las decisiones y acciones que se adelantan en la actualidad, especialmente, por parte de organismos internacionales. Existe una marcada tendencia liberal en una buena parte del mundo, que considera a la libertad como el valor básico que integra el contenido de la justicia, al punto que, en el caso de Rawls, es colocada lexicográficamente como el principio prioritario sobre el que se construye la justicia social.

En síntesis, asistimos a un momento histórico en el que la libertad se ha reducido al querer $y$ al elegir lo que se quiere, con indiferencia respecto de si lo que se elige es bueno o malo, pues eso pertenece a la esfera de la autonomía de la voluntad de cada sujeto. A ello, todos tenemos derecho, sin limitaciones de sexo, condición social o edad, y por eso se predica la posibilidad de desplegar actos libres a niños y adolescentes; $y$ como esa libertad no es absoluta, porque su límite principal es la libertad del otro, el ordenamiento jurídico tiene que entrar como herramienta para garantizarle a cada uno, la mayor libertad posible, buscando no afectar la libertad del otro. Tarea compleja y difícil, puesto que esto lleva, indefectiblemente, a la confrontación social, toda vez que, cuando cada uno quiere desplegar su libertad, sin un referente a lo bueno y verdadero, eso termina lesionando los derechos del otro, quien a su vez necesitará 
defenderse por mera tendencia natural, y va a querer también desplegar su libertad; la consecuencia: una violencia generalizada que ahora queremos solucionar con la tolerancia que, en palabras de Arthur Kaufmann, quien reformula el imperativo categórico kantiano en términos de tolerancia, no puede concebirse de manera negativa, esto es, "aguantar", sino que tiene que connotarse de manera positiva, es decir, "aceptar" (Kaufmann, 1999). Teóricamente, la cosa parece perfecta; empero, el problema, en la realidad -especialmente en los círculos de convivencia más íntimos como la familia-, sigue latente: iaceptar hasta dónde? a un hijo ise le tolera o se le ama? Kaufmann, como buen discípulo de Radbruch, sigue su tesis de que el límite de la tolerancia es la intolerancia. No obstante, ahí la cosa se complica aún más, porque Radbruch pensaba que esa intolerancia refería a la ausencia de justicia in extremis (1980) -o arbitrariedad legal-; pero como dentro del sistema de pensamiento idealista la justicia no puede ser el dar a cada uno lo suyo (el "suum cuique tribuere" del Digesto de Ulpiano) -porque esa fórmula es "vacía", es "tautológica"-, sino que su significante es relativo, se sigue de cerca la línea kelseniana que sostiene que la justicia es "la de la libertad, la de la paz, la justicia de la democracia, la justicia de la tolerancia" (Kelsen, 2001, p. 62). Entonces, entramos en un círculo vicioso, en un laberinto sin salida: libertad, confrontación social, tolerancia, justicia, libertad, confrontación, tolerancia, justicia, libertad. Y los problemas, sin solución; y la realidad, "clamando" porque se le tenga en cuenta.

Entonces, ¿ipor qué hemos de extrañarnos de los actuales niveles de alcoholismo, drogadicción, promiscuidad sexual, etc., si cada uno puede hacer lo que quiera producto del libre desarrollo de su personalidad, lo cual, además, es garantizado por el derecho? Esa ruptura entre la razón teórica y la razón práctica; entre la ciencia y la moral, hecha por Kant, y que luego Kelsen llevó a la ciencia del derecho, sigue dando frutos indeseados. Y aunque muchos teóricos del derecho post-kelsenianos han intentado superar, no lo han logrado porque, en el fondo, siguen los caminos del filósofo de Königsberg que fundamentó la moral en el sujeto, en la autonomía de la voluntad, frente a lo cual la ciencia -en este caso el derecho- tiene muy poco qué decir. El sistema filosófico adoptado -el del idealismo-, no les permite ir más allá de donde han ido: reconocer que la injusticia es contraria a la dignidad humana, pero a la vez, ver en la libertad -reducida a la elección-, el mayor bien del hombre. Y como lo segundo genera lo primero, cuando la realidad pide cuentas, las contradicciones son palmarias: por esa vía no hemos podido salir del laberinto y no lo vamos a hacer.

¿Libertad reducida a la mera elección? Sí, recuérdese que para Kant la verdadera libertad no está en realizar actos racionales, pues la reflexión es efecto y no causa de nuestros actos (García Morente, 1991, p. 162). Así, la moralidad se haya en lo íntimo del sujeto con indiferencia respecto del bien y el mal, pues ellos son conceptos derivados y no primitivos. ¿Y los valores? Son simplemente ideales de conducta que, si se sigue el imperativo categórico, se buscan; pero si la autonomía de la voluntad no se orienta hacia ellos, ni modos hay que aceptarlo, pues es el despliegue del libre desarrollo de la personalidad. Y como en Kant la religión expresa esos ideales, moral y religión se vuelven inseparables, al punto de confundírseles. El derecho como ciencia tiene que valorar los actos externos, en el campo de la libertad personal no tiene nada que decir.

\section{LA ANTÍTESIS: LIBERTAD ENTENDIDA COMO EL "OBRAR HUMANAMENTE"}

En el realismo filosófico encontramos una puerta de entrada distinta para la intelección de la realidad $-y$ allí de la libertad- que, a diferencia de lo planteado por el idealismo moderno, no sólo hace una defensa de la fundamentación de la libertad 
desde el ser (metafísica), sino que además considera que dicha fundamentación es imprescindible: es la puerta de la "aprehensión del ser" a la que refiere Etienne Gilson en "El realismo metódico". Desde este sistema de pensamiento, cuando el hombre actúa, revela su propia naturaleza, pues el obrar sigue al ser (operatio sequitur esse); el hombre es acción libre y esa dinamicidad nos muestra, a su vez, la especial excelencia de la persona humana, esto es, su especial dignidad respecto de los demás seres existentes (Cárdenas \& Guarín, 2006, parte I).

Desde cuando Kant, en su dialéctica trascendental sacó a la metafísica por la puerta de atrás del conocimiento, al considerarla una pseudo-ciencia ocupada de meras "ideas", de nada real, la hizo entrar en descrédito. Muchos aún creen que porque lo dijo Kant, así es. No olvide el lector, que las cosas que se dicen valen por lo que dicen y por quien las dice. La filosofía primera, a la que aludía Aristóteles -y que después fue llamada "metafísica" por obra de Andrónico de Rodas, según algunos historiadores-, lejos de indicar el estudio de algo enteléquico -la cosa en sí no cognoscible para Kant-, indica ese inquirir propio de la inteligencia humana, respecto de la realidad misma de las cosas. La metafísica, por ello, no es otra cosa que el compromiso del conocimiento, propio del hombre, con la verdad de las cosas, con el "de suyo" de las cosas, tal como lo refiere en varias de sus obras el filósofo español Xavier Zubiri, que no depende del hombre -así sea reunido con otros para consensuar-, sino que está en la cosa misma. La metafísica, así entendida, es la expresión más alta de la capacidad y la audacia de la inteligencia humana. En esa línea de reflexión, cuando Tomás de Aquino habla del hombre como "acción libre", con una naturaleza que indica un principio de operación que lo hace una criatura elevada respecto de los demás seres, lo que está haciendo no son elucubraciones sobre lo que es el hombre, sino que está indicando lo que es la verdad del hombre. Esa indagación metafísica parte de la observación de la realidad misma del "humano", captada -no creada ni inventada- por la razón, a partir de la experiencia que, para el de Aquino, es la fuente básica del conocimiento humano. De esta manera, en el realismo -a diferencia de lo que sucede con muchos filósofos herederos del idealismo moderno-, la fuente de conocimiento es la realidad misma $y$, aunque el juicio o proposición sobre lo que algo es un producto de la inteligencia humana, esa inteligencia tiene que estar atenida indefectiblemente a la realidad; si fuera de otra forma, sería imposible predicar la falsedad de un juicio. Así pues, no es una realidad que se teoriza por el hombre, y que se vuelve "objectum" producto de sus categorías mentales, lo cual conduce a formular ficciones como las contenidas en muchas de las teorías actuales que existen respecto de del derecho, la justicia y la libertad, sino que es una realidad que es y existe, con independencia del hombre, y que estamos llamados a captar, conocer, penetrar y respetar en su verdad.

En este orden de ideas, en términos realistas, no es posible hablar de libertad haciendo abstracción de lo que es la realidad misma de la persona humana. Esa "filosofía primera" de la persona, nos la muestra como un ser racional, que tiene dominio sobre sí mismo, que es capaz de ser dueño de sí, que puede autogobernarse, que es sociabilidad y que es teleológico por naturaleza, porque es el único ser capaz de dar sentido a su vida y a las cosas entre las que está inmerso, pues es un ser de inteligencia y voluntad. Esas potencias humanas tienen como objeto la verdad y el bien, sin los cuales la vida humana personal y social sería inviable. De allí lo grave que es el que la modernidad haya invertido la ecuación inteligencia-verdad y voluntad-bien: ya no es la verdad y el bien los que nos liberan, sino que es la libertad la que nos hace "verdaderos y buenos". Como somos seres para la verdad y el bien -somos facientes veritatem-, la libertad no puede ser concebida como un "a priori ontológico", sino que es vocación, llamado, 
dinamicidad, realización, liberación; de allí que libertad y madurez sean inseparables. Por eso, de un niño, aunque se puede afirmar que tiene la potencia volitiva, no se puede afirmar, con verdad, que es libre.

Frente a esa concepción de la libertad como ausencia de restricciones para hacer cosas, cuyo único límite es la libertad del otro y el orden jurídico; valor que constituye el eje gravitacional sobre el cual giran los demás valores jurídicos, el realismo metafísico plantea una libertad que, bien podríamos definir como "obrar humanamente" (Gevaert, 2000). Por eso, es una libertad que tiene un sentido, un para qué: el señorío del hombre sobre su ser; de otra manera no nos diferenciaríamos de las demás especies animales. Ese "obrar humanamente" implica por parte del hombre que realiza la acción, un respeto total por la realidad -objeto de su inteligencia-, que nos muestra que en el hombre hay unas tendencias de las que todos nos podemos dar cuenta: la preservación, conservación y continuidad de la especie, la tendencia a vivir en sociedad y la tendencia a buscar la verdad y el bien (S.T. I-II, q. 94, 2), y que constituyen un núcleo fundamental desde el cual es imposible tener una correcta intelección de la libertad humana. Por eso, la libertad lejos de ser una libertad de indiferencia respecto de lo bueno y lo malo -de "vivir como cada uno quiera"-, o una libertad cuyo único límite es la libertad del otro, es "autarquía" y "alteridad" plenas; es en definitiva vivir, según la virtud de la prudencia: ser "sibi providens", dueño de sí.

Ese "de suyo" humano -en términos zubirianos-, muestra además que es imposible separar la libertad de la dimensión teleológica, que es otro radical del ser humano. A diferencia del animal, el hombre es capaz de dotar su vida de sentido. La relación que existe en la filosofía realista entre la libertad y el sentido es inescindible. Nadie duda de que el acto propio de la libertad es la elección que hace el sujeto; empero, esa elección implica el saber lo que se hace y por qué se hace. Es por ello que la ignorancia, es una de las talanqueras más grandes, que impide vivir en auténtica libertad. El obrar humano es un obrar con "sentido", un obrar de fines. Por eso, es un verdadero drama ver, cómo nuestros jóvenes se pierden en el sin sentido, invocando el libre desarrollo de su personalidad. La antropología realista no es dualista ni reduccionista $y$, por eso, si bien es consciente de que la libertad implica un querer, propio de la voluntad, éste tiene que estar precedido de un juicio de razón que permite discernir lo que ha de evitar y lo que ha de procurarse (ST. I, q. 83, art 1). A un perro se le puede amaestrar para que haga cosas - por ejemplo, el trasladar ladrillos de un lado a otro, los cuales pueden servir para construir un edificio- pero jamás sabrá qué hace, por qué lo hace y para qué lo hace. El hombre, a diferencia del perro, realiza esas mismas acciones -llevar bloques o ladrillos de una lado a otro-, pero las puede dotar de sentido, dándoles un "telos" -por ejemplo, el de construir una casa para su familia-. Ahora bien, como el fin último al que tiende el hombre es la plenitud de su ser, y plenificándolo encuentra su felicidad, la libertad del hombre es libertad para el bien y la verdad, pues de no ser así, sería, nada más y nada menos, que la propia negación del ser. Por eso el realismo ve los límites de la libertad, no en la libertad del otro, pues eso termina generando violencia -ya que los límites son para superarlos si se quiere realizar el propio capricho-, sino en la propia condición humana que inclina hacia la verdad y el bien. Por eso, la libertad del realismo no es una libertad de indiferencia, ni una libertad para la confrontación social y se presenta como un buen camino para superar los graves problemas sociales por los que atravesamos, de los que los medios de comunicación social nos informan a diario: violencia, corrupción, promiscuidad sexual, alcoholismo, drogadicción..., todos ellos producto de una errada concepción del hombre y de su libertad. Seguramente alguien pensará que lo afirmado implica la negación del 
mal y la pretensión de conformar una sociedad de ángeles; eso no es así. La existencia de mal y de la ignorancia, es una realidad; pero eso no significa que el hombre sea un ser para el mal y la ignorancia. Aquí nuevamente enfatizo en la vida del hombre, en su libertad, como una llamada y una tarea por realizar. Ciertamente, el hombre puede obrar el mal, pero cuando obra el mal se vuelve contra sí y contra los otros; por eso, de su actuar no se pude predicar que sea libre. Como bien lo afirma el Aquinate: "querer el mal no es libertad, ni parte de la libertad, sino cierto signo de ella" (De Veritate 22, 6).

\section{SÍNTESIS: EDUCAR PARA LA LIBERTAD}

Hemos discurrido por las sendas que el idealismo y el realismo nos señalan respecto del concepto de libertad. Personalmente, después de haber navegado muchos años por los mares del existencialismo de corte idealista, ahora he llegado al convencimiento de que el realismo es un sistema de pensamiento que, por su respeto por la verdad de las cosas, constituye una base gnoseológica que es sólida; base que tanto preocupa a los filósofos y teóricos del derecho en la actualidad, que con una actitud honesta, tienen un deseo sincero de dar una fundamentación a conceptos como el de la libertad, que supere el individualismo y subjetivismo extremos, que generan tanto daño social. Sin duda alguna, Rawls, Kaufmann, Bobbio, Alexy, Dworkin, se vieron -y se ven los que aún viven- profundamente afectados por las desigualdades e injusticias que campean en la sociedad, e indagan respecto de la manera como el derecho puede contribuir a su superación. Para todos nosotros, realistas o idealistas, la injusticia, la violencia, la drogadicción, etc., no representan un bien sino un mal social personal y social, $y$ tenemos que buscar la forma de superarlos. A nosotros nos llama poderosamente la atención el hecho de que muchos de estos teóricos, no obstante, hablar de su abierto rechazo a cualquier tipo de consideración metafísica (las razones de ello las expuse en la introducción de este escrito), realmente no pueden dejar de aludir a ella, quizá porque, como lo dice con sabiduría Bretón (1973, p. 15), "nadie puede escapar a la jurisdicción del ser". Es el caso de Kaufmann que habla de la unicidad e irrepetibilidad del ser humano -conceptos metafísicos por excelencia- al abordar el tema de la clonación humana (Kaufmann, 1999); también es el caso de Rawls, que en la página 457 (en el pie de página) de su Teoría de la justicia, habla de lo natural como un atributo de las cosas que se capta por la razón, lo cual, sin duda, tiene un profundo tinte realista (Cárdenas \& Guarín, 2010, parte II).

En ese orden de ideas, aunque innegablemente hay enormes distancias entre la concepción de la libertad heredada de la modernidad, y las tesis del realismo metafísico sobre el particular, que han sido puestas en evidencia a lo largo de estas líneas, en el fondo, la búsqueda honesta de la verdad por parte de los pensadores pertenecientes a uno u otro sistema los acerca: verdad que pasa por la necesidad de respeto por el hombre, lo cual no puede ser relativizado. Con esto quiero mostrar que dentro de cualquier sistema de pensamiento hay unas verdades que son irreductibles pues refieren a la propia realidad humana como ser individual y social.

Tenemos el convencimiento de que la única libertad posible y real es aquella que es expresión del dinamismo del ser del hombre como persona; por eso, debemos educar para la libertad mostrándole al hombre de hoy lo que ES y, a partir de allí, lo que es la libertad humana. $Y$ dentro de esa realidad humana, producto de esa labor educativa, hacer un énfasis muy fuerte en la necesidad de verdad y de bien que tenemos los seres humanos. El hombre de hoy se ha distanciado de la verdad, la ve como algo "añadido" (Zubiri, 1987, p.7), lo cual es muy grave, porque sin verdad y sin bien 
el hombre se pierde a sí mismo, dado que, por su propia condición, necesita de la verdad y se inclina hacia ella (Millán, 1987).

El hombre educado para la libertad, es capaz de dar cuenta de lo que hace $y$ de ser señor de sus actos; esa libertad, lleva a ver al otro, no como cosa más a la que cada uno objetiva, sino como un "alter" con quien con-vivo y no con quien confronto: allí la libertad se plenifica "por" y "en el" amor. Entonces, el otro deja de ser un límite para mi libertad y se convierte en aquel en cuya compañía realizo mi libertad con respeto y reciprocidad.

En definitiva, se trata de volver a recuperar al ser humano en cuanto realidad personal. La persona es el fundamento del derecho; por eso, Kaufmann, plantea que la validez del derecho pasa por su ser "análogo a la persona" (Gevaert, 2000). Sin embargo, no podemos caer en el error de llenar de cualquier contenido el significado de esa realidad personal del hombre, como si se tratara de una mera "flatus vocis". Como lo señala el profesor Edwin Horta (1988), la persona humana tiene una capacidad para ser protagonista de su vida, que es de naturaleza jurídica y, por eso, el ser persona humana constituye un verdadero derecho. La vida humana no tiene una dimensión meramente biológica: es biográfica, es decir, que el hombre, por el hecho de ser persona, puede ir "escribiendo su vida", producto de su capacidad de adueñarse de su existencia, por sus potencias intelectiva y volitiva. Es por eso que se le llama "persona": un ser que puede actuar por sí, sonar por sí (per-sonare), sus actos parten de sí y se encaminan hacia sí. De allí que afirme el eminente jurista: "la miseria más grande del ser humano no está en la carencia de alimento, sino en la carencia de condiciones para ejercer su libertad" (Horta, 1988, p. 54).

Por lo expuesto, quitarle al hombre su libertad -no me refiero sólo a la libertad física, sino a esa posibilidad de escribir su biografía-, es despojarlo de algo suyo, de un radical que le es propio, y por ende, hacerlo constituye la más grande de las injusticias: "la más grande miseria humana", como diría Kant. Educar para la libertad es conducir al hombre de hoy a superar su amnesia ontológica, es decir, es llevarlo a redescubrirse a sí mismo, a reivindicarse: esa es nuestra tarea como juristas porque es al jurista al que le interesa la justicia.

La llamada que hacemos al lector de estas reflexiones es a trabajar por la educación en la verdad y en el bien, sin los cuales es imposible hablar de libertad humana. En cumplimiento de esta labor, hay que tener mucho cuidado para no caer en el reduccionismo actual en el que se halla sumida la educación: un mero transmitir conocimientos; educar -bien lo decía Tomás de Aquino al finalizar la Summa Theologiae- es la conductio et promotio usque statum perfectum hominis, por lo cual, implica no sólo formar en el comprender y el hacer, sino también en el obrar moral y el convivir: las cuatro dimensiones de la acción humana. Si no superamos la nefasta idea de que un docente no tiene porqué formar la vida moral de sus estudiantes, sino que debe circunscribirse solamente a la formación del intelelecto, no saldremos de la crisis actual. El maestro es el que forma integralmente, esto es, la inteligencia y la voluntad del dicente: ¡esa es una enorme responsabilidad histórica! Y, para ello, no se puede olvidar que hay una cosa que es imprescindible: el ejemplo. Siguiendo la idea de Santo Tomás de Aquino en el De Magistro, podríamos afirmar que el docente, que es verdadero maestro, educa sobre todo con su ejemplo: ejemplo en la búsqueda de la verdad y del bien; en el camino de plenificación de la propia persona; en el cultivo de la virtud de la studiositas y de la prudencia que lleva al bien obrar. Cuando se vive de esta manera, se es verdaderamente feliz. Yo creo que ese es un reto muy grande para los docentes de hoy: mostrarle a sus dicentes que es posible estar alegre y ser auténticamente feliz viviendo en la verdad y en el bien, y no sometidos a los vicios que generan disipación y pérdida de la libertad, y que, a mediano y largo plazo, causan profundas 
tristezas, pues ellos llevan a vivir conforme a lo que no se es.

\section{REFERENCIAS}

Bretón, S. (1976). Santo Tomás. Madrid: Edaf.

Cárdenas, A. \& Guarín, E. (2006). Filosofía y teoría del derecho: Tomás de Aquino diálogo con Kelsen, Hart, Dworkin y Kaufmann. Bogotá: Universidad Santo Tomás.

Cárdenas, A. \& Guarín, E. (2010). Filosofía de la política y del derecho: Tomás de Aquino diálogo con Bobbio, Chomsky, Rawls y Alexy. Bogotá: Universidad Santo Tomás.

Copleston, F. C. (1960). El pensamiento de Santo Tomás. México: Fondo de Cultura Económica.

García, M. (2004). La filosofía de Kant. Bogotá: Cristiandad.

Gilson, E. (1974). El realismo metódico. Madrid: Rialp.

Horta, E. (1988). La propia persona como derecho... En: Dikaion 2, Bogotá: Universidad de la Sabana.
Kant, I. (1977). Crítica de la razón pura. México: Porrúa.

Kaufmann, A. (1999). Filosofía del derecho. Bogotá: Universidad Externado de Colombia (traducción).

Millán, A. (1987). El interés por la verdad. Madrid: Rialp.

Radubruch. (1980). Arbitrariedad legal y derecho supralegal. En: El hombre en el derecho. Trad. Aníbal del Campo. Buenos Aires: Depalma.

Rawls, J. (2000). Teoría de la justicia. México: Fondo de Cultura Económica.

Tomás de Aquino. (1954). Suma teológica. Madrid: BAC.

Tomás de Aquino. (2003). Opúsculos y cuestiones selectas. Madrid: BAC.

Vernaux, R. (1984). Historia de la filosofía moderna. Barcelona: Herder.

Zubiri, X. (1987). El hombre y la verdad. Madrid: Alianza Editorial. 